\title{
Children's oral health
}

Sir, we thoroughly enjoyed reading the article entitled COVID-19 and Community Dental Services: The challenges ahead and wished to contribute some additional thoughts regarding children's oral health during the COVID-19 pandemic. $^{1}$

In response to the global COVID-19 crisis, routine dentistry and dental theatre lists were suspended, and subsequently many patients are still awaiting dental surgery. Whilst triaging is ongoing within paediatric departments to ensure those most likely to be at risk of pain and infection are a priority, many children remain on waiting lists and continue to suffer from dental caries. We are concerned more extractions may be necessary and this would further lengthen dental general anaesthetic (GA) waiting lists. In addition, we know GA is associated with anxiety post-procedure which can have repercussions on future dental attendance and thus reoccurring attendance for dental GA. ${ }^{2}$ A further factor will be the reduction in numbers of aerosol generating procedures that can be carried out in terms of fallow time and layout of paediatric dentistry polyclinics. It is noted that the Hall technique and use of sliver diamide were non-AGP additions to the latest ODCO guidance. ${ }^{3}$

We wholeheartedly agree that preventative dentistry is more important now than ever before. Understandably, NHS England has been focusing on the development of urgent dental care centres during the COVID-19 pandemic, however it is important it continues its efforts in supporting innovative prevention focussed programmes such as the Flexible Commissioning in Yorkshire and the Humber. ${ }^{4}$ At a time when faceto-face consultations are reduced, dental practices can utilise other platforms to help disseminate important oral health messages. General medical practice data showed a decline in face-to-face consultations from $>70 \%$ to $23 \%$ within weeks of the pandemic. ${ }^{5}$ Dental practices have followed suit but could be creative with remote technologies and oral health promotion messages.

Dental health education in schools has been found to enhance oral-health related knowledge, attitude and behaviour. ${ }^{6}$ With children being kept home from school, many may be missing out on key oral health promotion strategies which could have implications for their long-term health. As with the Happy Teeth Outreach and Teeth Team programmes, other national school initiatives are also affected by the pandemic. PhunkyFoods, an organisation who aim to improve dietary and physical activity habits in early years settings, have utilised the time during school closures putting together home learning packs for families. Additionally, school fluoride varnish and supervised toothbrushing programmes have been suspended, and this combined with the prospect of poorer diets and frequent snacking whilst at home, raises serious concern for dental caries. We note in a recent UNICEF report, families facing job and income loss will struggle to provide nutritious meals for their children.?

It is encouraging to see other initiatives being taken to help oral health at this time, be it CBeebies' Dr Ranj oral health videos or the community donating toothpaste and toothbrushes to local food banks here in Yorkshire and the Humber.

We are waiting with anxiety to see the true outcome of the pandemic on dentistry and on child oral health. However, it is already clear that a positive outcome of the pandemic has been hastened advances in both technology and community spirit and we believe that by seizing the time that we have, as well as these resources, we can work now to find innovative ways to mitigate some of the damage caused.

O. Barraclough, Z. Mustufvi, S. Serban, S. Grant.

Leeds

\section{References}

1. Westgarth D. COVID-19 and Community Dental Services: The challenges ahead. BDJ In Pract 2020; 33: 14-19.

2. Goodwin M, Sanders C, Davies G, Walsh T, Pretty I A. Issues arising following a referral and subsequent wait for extraction under general anaesthetic: Impact on children. BMC Oral Health 2015; 15: 3.

3. Office of Chief Dental Officer England. Standard operating procedure. Transition to recovery. Available from: https:// www.england.nhs.uk/coronavirus/wp-content/uploads/ sites/52/2020/06/C0575-dental-transition-to-recoverySOP-4June.pdf (Accessed June 2020).

4. Mustufvi Z, Barraclough O, Hearnshaw S, Whiston S, Grant S, Serban S, Douglas G. Flexible Commissioning: A prevention ansd access focused approach in Yorkshire and the Humber. BDJ In Pract 2020; 33: 20-22.

5. Marshall M, Howe A, Howsam G, Mulholland M and Leach, J. COVID-19: a danger and an opportunity for the future of general practice. Br J Gen Pract 2020; 70: 270-271.

6. Priya P G, Asokan S, Janani R, Kandaswamy D. Effectiveness of school dental health education on the oral health status and knowledge of children: $A$ systematic review. Indian J Dent Res 2019; 30: 437-449.

7. Unicef. Children in lockdown: What coronavirus means for UK children. 2020
Jason Wong new Deputy Chief Dental Officer

NHS England and NHS Improvement and the Chief Dental Officer for England have announced the appointment of Jason Wong MBE as Deputy Chief Dental Officer for England.

Jason will work alongside Sara Hurley and Eric Rooney (Deputy CDO) in collaboration with local and regional teams to deliver improved outcomes for patients, and champion the role of dentists and dentistry within the health system.

Jason is a general dental practitioner who qualified from the University of Birmingham in 1995 and also holds a Diploma in Postgraduate Dental Studies from the University of Bristol. He is a partner at the Maltings Dental Practice in Grantham. He was awarded an MBE for services to Dentistry and Oral Health in 2020.

Chief Dental Officer, Sara Hurley said: 'Jason has a track record for outstanding delivery as a Local Dental Network Chair. $\mathrm{He}$ is a respected practitioner and trainer and a notable champion of children's oral health. His experience and diverse portfolio will be invaluable as we navigate the ongoing challenges of COVID-19 and build on the integrated team approach alongside our colleagues in the wider health and social care sector.'

Jason added: It is a privilege to be appointed as Deputy Chief Dental Officer for England. I am very much looking forward to joining the Office of the Chief Dental Officer and working with the entire dental family.'

Jason will share the role with Deputy Chief Dental Officer Eric Rooney MBE.

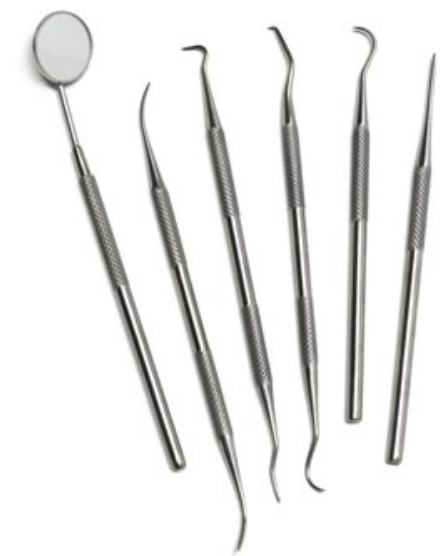

